\title{
Transatlantica
}

Revue d'études américaines. American Studies Journal

\section{Edward Curtis, In the Land of the Head Hunters}

(version restaurée) 2013 [1914], 67'

Camille Joseph

\section{(2) OpenEdition}

Journals

Édition électronique

URL : https://journals.openedition.org/transatlantica/6426

DOI : 10.4000/transatlantica.6426

ISSN : $1765-2766$

Éditeur

Association française d'Etudes Américaines (AFEA)

Référence électronique

Camille Joseph, «Edward Curtis, In the Land of the Head Hunters », Transatlantica [En ligne], 1 | 2013,

mis en ligne le 12 avril 2021, consulté le 01 février 2023. URL : http://journals.openedition.org/

transatlantica/6426 ; DOI : https://doi.org/10.4000/transatlantica.6426

Ce document a été généré automatiquement le 1 février 2023.

\section{cc) (i) $(\Theta)$}

Creative Commons - Attribution - Pas d'Utilisation Commerciale - Pas de Modification 4.0 International - CC BY-NC-ND 4.0

https://creativecommons.org/licenses/by-nc-nd/4.0/ 


\title{
Edward Curtis, In the Land of the Head Hunters
}

(version restaurée) 2013 [1914], 67’

\author{
Camille Joseph
}

\section{RÉFÉRENCE}

CURTIS, Edward, In the Land of the Head Hunters (version restaurée), 2013 [1914], 67'.

1 En 1911, Edward S. Curtis (1868-1952) entreprend de faire un film sur les tribus indiennes vivant sur lîle de Vancouver, à l'ouest de la Colombie britannique au Canada. Photographe professionnel, Curtis connaît déjà les Kwakiutl, auxquels il a consacré un tome de The North American Indian, œuvre monumentale parue en vingt volumes (1907-1930) mêlant textes à visée ethnographique et quelque 2000 photographies ${ }^{1}$. Curtis veut saisir l'Indien avant sa disparition complète (the vanishing Indian), n'hésitant pas à mettre en scène et à costumer ses personnages. In the Land of the Head Hunters, sorti à New York et à Seattle en 1914, se présente là encore comme une sorte de reconstitution historique: vêtus des habits traditionnels en écorce de cèdre, des Kwakiutl exécutent devant la caméra les coutumes, rites, fêtes et jeux de leur tribu dans un cadre naturel. Le film de Curtis est ainsi le premier à recourir à un casting entièrement composé d'Indiens, huit ans avant Nanook of the North de Robert F. Flaherty (1922). L'autre originalité de In the Land of the Head Hunters repose sur la trame narrative élaborée servant d'arrière-plan aux reconstitutions des scènes traditionnelles. Motana, fils d'un grand chef indien, part faire une retraite initiatique dans la forêt au cours de laquelle il voit apparaître en rêve sa future femme, Naida. Mais celle-ci a été promise par son père au Sorcier de l'île voisine. Le clan de Motana lance une première attaque sur le clan du Sorcier, dont on craint la puissante magie noire. Ce dernier a la tête coupée, puis le mariage est célébré en grande pompe. Mais le frère de la victime, Yaklus, a réussi à s'échapper et prépare sa revanche. Il met à sac le village de Motana, 
laissé pour mort, et capture la jeune Naida. Une dernière expédition punitive est lancée, qui se solde par la mort de Yaklus et le retour triomphal du héros.

Curtis réalise son film avec l'espoir de profiter du succès que connaissent alors les documentaires romancés, nouveaux films d'un genre hybride dans lesquels un scénario « classique » est tourné dans des contrées lointaines et exotiques. En outre, les Kwakiutl ont déjà une place dans l'imaginaire du public américain. Leurs mâts totémiques et masques à transformation spectaculaires ont fait leur entrée au Musée d'histoire naturelle de New York dès les années 1890 sous l'impulsion de l'anthropologue Franz Boas, qui leur a déjà consacré, en 1914, vingt années de recherches. Curtis arrive donc en terrain relativement bien balisé d'un point de vue anthropologique. Les Kwakiutl eux aussi sont familiers des anthropologues, agents coloniaux et touristes qui débarquent sur leurs côtes. George Hunt, né sur l'île de Vancouver et élevé chez les Kwakiutl, va jouer un rôle d'intermédiaire fondamental. Célèbre pour sa collaboration avec Boas, il apporte également une aide décisive à Curtis. Avant le tournage, Hunt se documente sur certaines coutumes et collecte des objets traditionnels (tels que masques, couvertures, hochets ou tambours) qui seront utilisés dans le film² ${ }^{2}$. Durant le tournage, il participe à la production, à la direction d'acteurs et à la traduction; son propre fils interprète le rôle principal. Tous les Kwakiutl participent à la sélection des cérémonies et à leur mise en scène, mêlant danses authentiques et chorégraphies improvisées sur le moment. Dans un contexte d'interdiction du potlatch ${ }^{3}$, rituel au cœur de la vie des peuples de la côte nord-ouest, les Kwakiutl se saisissent de l'opportunité que représente le film : la dimension commerciale du projet leur permet de sauvegarder sur bobine des danses et des traditions menacées de disparition sans risquer d'être condamnés par les autorités locales ${ }^{4}$. Projeté sur les écrans américains jusqu'en 1916, le film n'atteint pas les scores escomptés par Curtis, qui espérait utiliser les recettes pour financer la suite de ses explorations. En dépit de critiques fort élogieuses, dont l'une va même jusqu'à comparer cette " épopée indienne " au Parsifal de Wagner ${ }^{5}$, le film disparaît des écrans. Une copie est achetée en 1923 par le Musée d'histoire naturelle de New York, avant de disparaître elle aussi des archives, sans doute à cause de la fragilité des pellicules en nitrate utilisées à l'époque.

Il s'en est fallu de peu que In the Land of the Head Hunters ne connaisse le destin de tant d'autres films ethnographiques réalisés dans les premières décennies $d u x^{e}$ siècle: oubliés sur les étagères des musées européens et nord-américains, détériorés sous l'effet du temps et des mauvaises conditions de conservation, voire carrément détruits et disparus à tout jamais. En 1947, le Field Museum de Chicago hérite de l'unique copie existante du film, récupérée dans une décharge de la ville. Elle est en très mauvais état et incomplète. En 1973, Bill Holm et George Quimby, spécialistes de l'histoire de l'art des peuples de la côte nord-ouest, parviennent cependant à produire une version de 45 minutes dont l'innovation principale réside dans l'ajout d'une bande-son : des Kwakiutl associés au projet enregistrent des dialogues et des chants, redonnant ainsi voix à leurs ancêtres. C'est alors un Curtis ethnologue qui émerge au cours de cette décennie, loin du Curtis sensationnaliste du début du siècle. À la faveur du mouvement américain de la contre-culture, il est en effet célébré en héros des cultures indiennes et pionnier du film ethnographique ${ }^{6}$. Dans leur projet de restauration, Holm et Quimby se concentrent sur les éléments « authentiques " que Curtis a réussi à saisir, au détriment des aspects romanesques présents dans la version originale. Signe ultime du changement de statut du film, qui devient alors un document visuel unique présentant les dernières traces de 
la culture Kwakiutl du XIX ${ }^{e}$ siècle, son titre devient In the Land of the War Canoes. Ce nouveau titre éloigne le spectre du cannibalisme auquel les Kwakiutl furent longtemps associés. Paradoxalement, c'est une image elle aussi légendaire, mais plus noble, qui est convoquée à la place, celle du guerrier indien.

La décennie 1980 marque la démystification complète de Curtis, désormais épinglé comme le représentant d'un ethnocentrisme destructeur. Dans cette nouvelle lecture de son œuvre, les Indiens sont réduits au statut de victimes impuissantes : Curtis est accusé d'avoir mis en scène leur authenticité, d'avoir construit ses « Indiens » de toutes pièces. La photographie et le film représentent désormais autant de gestes de domination, d'enfermement dans les stéréotypes les plus grossiers que se partagent ethnologues, photographes et réalisateurs, le style primitiviste de Curtis servant dans son cas particulier de preuve irréfutable de sa vision profondément essentialiste des cultures indiennes, figées dans un espace atemporel. Ce procès en règle des images indiennes témoigne d'une défiance générale à l'égard du visuel, nécessairement synonyme de manipulation, et donc d'idéologie. Après la disgrâce du postcolonialisme, la version restaurée de In the Land of the Head Hunters se veut à ce titre une réhabilitation du film de Curtis et du film ethnographique en général. En 2006, deux chercheurs américains, Brad Evans (Rutgers University) et Aaron Glass (Bard Graduate Center), font une découverte importante : ils retrouvent une copie noir et blanc du film où apparaissent clairement la structure narrative qui avait disparu de la version de 1973, ainsi que les intertitres d'origine ; ils mettent également la main sur la bande-son de l'époque (une pièce pour orchestre du compositeur et chef d'orchestre John $\mathrm{J}$. Braham), des chants traditionnels enregistrés sur cylindre par Curtis, et des fragments de bobines nitrate en couleur. Le projet, coordonné par la U'mista Cultural Society, organisme de conservation de la culture Kwakiutl, entreprend de restaurer le film dans une version très proche de celle de 1914 : les intertitres sont réintroduits, des scènes coupées sont rajoutées et les couleurs sont restaurées (y compris dans la version numérisée actuelle). Des photogrammes réalisés par Curtis à l'époque remplacent les plans de trop mauvaise qualité. Le film s'allonge de quelques minutes (67') et retrouve son titre d'origine, preuve qu'il est maintenant possible de le replacer dans une histoire du cinéma où il n'apparaît plus comme un exemple-phare du documentaire ethnographique réaliste, mais comme une entreprise artistique audacieuse dont l'objectif était de faire de l'ethnographie un spectacle grand public.

5 La seule différence entre la version américaine et la version proposée au public français est la bande-son. Tandis que les Américains ont souhaité restaurer celle qui avait été choisie par Curtis à l'origine, c'est le compositeur et interprète Rodolphe Burger qui s'est vu confier la musique du film par les producteurs français. Des samples de voix indiennes mêlées à celle du rockeur accompagnent une guitare et une machine lançant des rythmes entêtants; un chant à la beauté saisissante erre entre les scènes. Cet anachronisme volontaire produit un effet de décalage par rapport au projet initial. Aux États-Unis, en effet, il s'agit de réconcilier Curtis et les Indiens, de travailler la mémoire nationale américaine et l'héritage du colonialisme en replaçant le film dans une histoire du cinéma. La restauration de In the Land of the Head Hunters ne se veut-elle pas finalement une sorte de happy-end hollywoodien? Avec sa bande-son contemporaine, qui revisite de façon pleinement assumée la transe indienne, la version française semble extraire le film du cycle des dénonciations, réhabilitations et réévaluations successives qui ont entouré toute l'œuvre du photographe-ethnologue aux États-Unis. 
À l'historicisation est préférée une expérience immédiate et sensorielle du film, présenté en nouvelle icône chamanique.

\section{Coming for the bride}

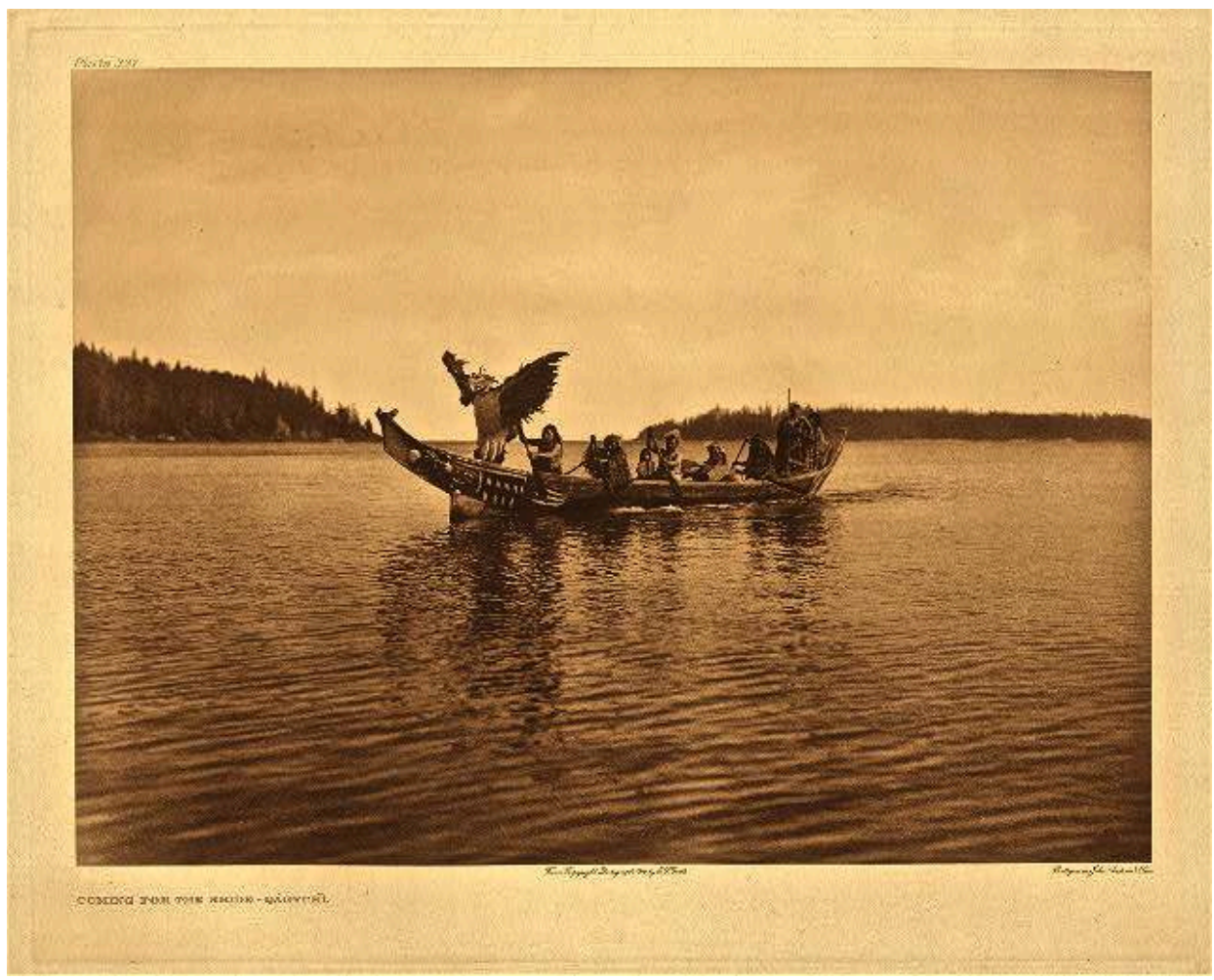

Edward Curtis, Coming for the bride, 1914, photogravure, $34 \times 43 \mathrm{~cm}$, Portfolio 10, Plate no. 337 (Northwestern University Library, Edward S. Curtis's « The North American Indian », 2003, http:// digital.library.northwestern.edu/curtis/).

Scène de l'arrivée des danseurs pour le mariage de Motana et Daina, figurant dans le volume de The North American Indian consacré au Kwakiutl. Ici, Oiseau-Tonnerre danse à la proue de l'un des canoës.

\section{NOTES}

1. Sur les photographies de Curtis, on renvoie en particulier à Mathilde Arrivé, "Utterly Lost?» L'Indien et la photographie à l'épreuve de l'(anti)-modernité dans The North American Indian d'Edward S. Curtis, Thèse de doctorat, Université Bordeaux III, 2009.

2. Ira Jacknis, "George Hunt, Collector of Indian Specimens », dans Aldona Jonaitis, dir., Chiefly Feasts : The Enduring Kwakiutl Potlatch, New York, American Museum of Natural History, 1991, 205.

3. Au Canada, le potlatch fut interdit de 1885 à 1951.

4. Voir le site du projet, http://www.curtisfilm.rutgers.edu/film/making-of-head-huntersmainmenu-34 (consulté le 15 octobre 2013). 
5. W. Stephen Bush cité par Kathryn Bunn-Marcuse, "Kwakwaka'wakw on film », dans Ute Lischke et David T. McNab, dirs., Walking a Tightrope. Aboriginal People and Their Representations, Waterloo, Wilfrid Laurier University Press, 2005, 308.

6. Les années 1960 sont un moment de redécouverte des films réalisés par les premiers grands anthropologues (Rudolph Pöch en Nouvelle-Guinée, Spencer et Gillen en Australie, etc.). Les premières archives du film anthropologique voient le jour à Göttingen en 1952, une branche américaine étant créée à la Pennsylvania State University en 1966.

INDEX

Thèmes : Trans'Arts

\section{AUTEURS}

CAMILLE JOSEPH

Université Paris 8 